\title{
Comparative Study on Two Methods Used in Obtaining 3D Printed Dental Models
}

\author{
MIHAELA PANTEA ${ }^{1}$, ROBERT CIOCOIU ${ }^{2 *}$, ANA MARIA CRISTINA TANCU ${ }^{3 *}$, DANIELA-MĂDĂLINA NINĂ ${ }^{4}$, \\ ALEXANDRU PETRE ${ }^{1}$, IULIAN VASILE ANTONIAC ${ }^{2}$, MARINA MELESCANU-IMRE ${ }^{3}$ \\ ${ }^{1}$ University of Medicine and Pharmacy Carol Davila, Faculty of Dental Medicine, Department of Fixed Prosthodontics and Occlusology, 17-23 \\ Plevnei Str., 010221, Bucharest, Romania \\ ${ }^{2}$ Politehnica University of Bucharest, Faculty of Materials Science and Engineering, Department of Metallic Materials Science, Physical \\ Metallurgy, 313 Splaiul Independentei., 060042, Bucharest, Romania \\ ${ }^{3}$ University of Medicine and Pharmacy Carol Davila, Faculty of Dental Medicine, Department of Complete Denture, 17-23 Plevnei Str., 010221, \\ Bucharest, Romania \\ ${ }^{4}$ Doctor, Private practice, 19 Ziduri intre Vii Str., Bucharest, Romania
}

The purpose of this study was to assess the accuracy of two $3 D$ printed dental models manufactured after intraoral/IO and extraoral/EO scanning. A dental study model (KaVo Dental GmbH/Germany) was used as a reference for this research; this model was scanned with an industrial scanner (XT H 225 ST/Industrial CT scan/Nikon Metrology Inc./U.S.A.) and a reference STL file was generated (coded M1). Two 3D printed models (Form2/FormLabs Inc./U.S.A.) were produced via IO scanning (TRIOS 3 Battery Cart/3 Shape/Denmark), respectively via EO scanning (Swing Dental Scanner/Dof Inc./South Korea) of the reference dental model. The 3D printed models obtained were scanned with the industrial scanner, resulting in other two STL files (coded M2, respectively M3). All the STL files obtained (reference M1; M2; M3) were compared in pairs, using a 3D analysis software. Good results were achieved in obtaining $3 D$ printed dental models via IO or EO scanning, yet, the $3 D$ printed dental model obtained via IO scanning (M3) showed slightly improved dimensional compatibility with the reference model (M1) in comparison with the 3D printed dental model manufactured via EO scanning (M2).

Keywords: 3D printed models, intraoral scanners, extraoral scanners

Accuracy (trueness and precision) of dental models, measurements' reproducibility on different study models, the materials from which these models are made, as well as the influence that different techniques of obtaining them have on their final quality, represent topical subjects for the scientific research in the field of modern dentistry.

A few years ago, laboratory scanning (extraoral scanning/EO) proved to provide better accuracy for dental models than intraoral scanning/IO [1]. Even relatively recently, in the years 2017/2018, the scientific literature reported that the conventional method / traditional impression technique was still the "best solution" for performing large prosthetic restorations, respectively for fixed prosthetic restorations of the entire arch, supported on natural teeth or implants [25].

On the other hand, according to the results of valuable in vitro [6-10] or in vivo [11- 13] studies conducted between 2010 and 2018, the idea that fixed prosthetic restorations obtained in digital flow (including intraoral/IO scanning) have a good marginal adaptation, equal to or better than those obtained by extaoral/EO scanning of the impression or of the dental model, is gaining significance. Furthermore, the measurements made on the printed models obtained after the intraoral/IO scanning did not show statistically significant differences when compared with the measurements made on the reference gypsum models, while the measurements made on the printed models obtained after impression scanning showed significant statistical differences when compared with those performed on the gypsum models [14]. Intraoral scanning is performed, however, under conditions that can generate inaccuracies in data aquisition: the presence of saliva can influence the capture of images; limited space for scanner access; tongue and cheek movements during optical impression [1]. In addition, for the intraoral scanning, the cost of purchasing the equipment remains quite high, and the physician must be "trained" properly for such a procedure, otherwise the time required for intraoral scanning may be longer than in the conventional impression. Nevertheless, as far as printed models are concerned, it has been proven quite convincingly in recent literature that modern printing techniques provide clinically acceptable dental models, therefore, these ones represent a viable alternative for clinical applications [15].

As the issues presented above are still controversial and need to be further explored, the purpose of this scientific paper was to perform an in vitro comparison of two methods of obtaining 3D printed dental models: a method using a laboratory scanner (extraoral scanner/EO), respectively, a method using an intraoral scanner/IO.

*email: ciocoiurobert@gmail.com, Phone: +40727796160 amctancu@yahoo.com, Phone: +40722664355

All authors have equally contributed to this paper 


\section{Experimental part}

In this in vitro study, a maxillary reference standard model (Frasaco GmbH/Germany) was used; an experienced doctor has made standard preparations for various types of prosthetic restorations on this model: 1.2. - ceramic crown;

2.4., 2.5. - partial crowns; 2.7. - MOD inlay. The reference model was fixed in a firm position on a support, to provide stability during the tests. The procedures performed during this study were made according to the manufacturers' recommendations, and the working protocol that was applied is presented in Fig. 1.

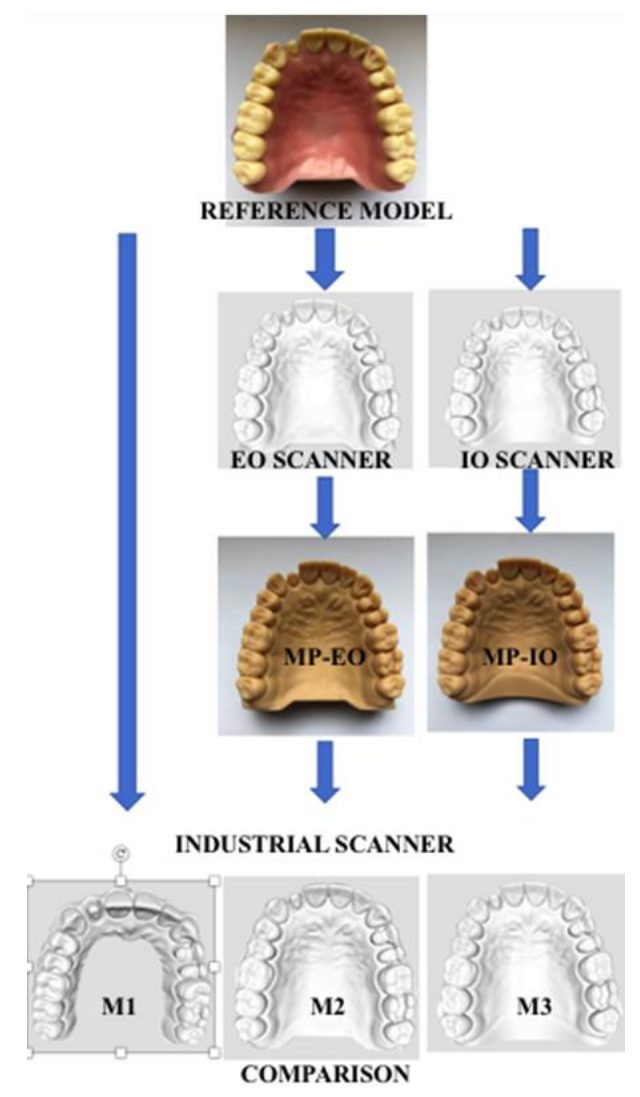

Fig. 1. Scheme of the experimental project

The reference model was initially scanned with an industrial scanner (XT H 225 ST/Industrial CT scan/Nikon Metrology Inc./U.K.) with an accuracy of approximately $6 \mu$, generating a reference STL file (coded M1). Subsequently, the reference model was scanned with a laboratory/extraoral scanner (Swing Dental Scanner/Dof Inc./South Korea) and an intraoral scanner (TRIOS 3 Battery Cart/3Shape/Denmark). Following the two scans, two separate STL files were obtained. Based on these two STL files obtained, two different printed models were produced, made from the same type of material and using the same printing system, according to the manufacturer's instructions (Form2/FormLabs Inc./U.S.A.). The printed models obtained were coded as follows: "MP-EO" / the printed model obtained after the extraoral scan, respectively, "MP-IO" - the printed model obtained after the intraoral scan. Both printed models (MPEO and MP-IO) were scanned, in turn, with the industrial scanner used initially (XT H 225 ST/Industrial CT scan/Nikon Metrology Inc./UK), resulting in two more STL files: a STL file corresponding to the printed model obtained after the extraoral scan - coded M2; a STL file corresponding to the printed model obtained after the intraoral scan - noted M3.

All three STL files (the reference one, M1; M2; M3) were superimposed in pairs using 3D analysis software (Geomagic Control X) to evaluate the trueness of the complete dental maxillary arch; the STL file coded M1 was used as a reference. The scanned images were super-imposed by means of the software's best-fit alignment method. Two alignment methods were used to observe the influence of this process on the results of the comparisons: an alignment conditioned by the region of interest chosen (outer surface of the teeth) and an alignment without preconditions, generated by the algorithm of the software, depending on the ability to recognize details (this type of alignment excludes intervention). 


\section{Results and discussions}

The comparative analyses were performed using the whole model, on the surface, the comparisons being made in pairs, between M1 and M2, M1 and M3, respectively, M2 and M3. Following the analyses carried out, the results obtained indicate, generally, an acceptable dimensional compatibility for all the models (Fig. 2-5).
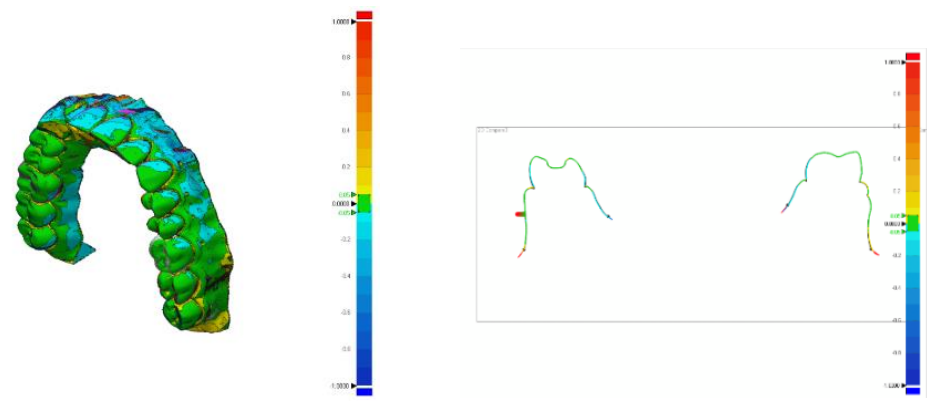

Fig. 2. 3D comparison between M1 vs M2, in 3D and 2D perspective (alignment conditioned by the region of interest selected)
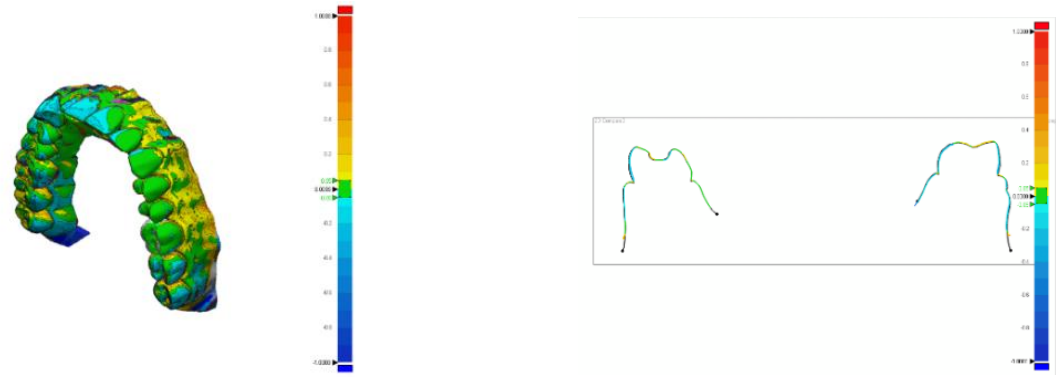

Fig. 3. 3D comparison between $M 1$ vs M3, in 3D and 2D perspective (alignment conditioned by the region of interest selected)

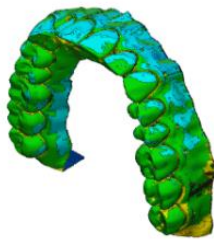

Fig. 4. 3D comparison between M1 vs M2 (automatic alignment)

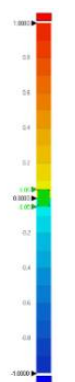

Fig. 5. 3D comparison between M1 vs M3 (automatic alignment)

Analysing the results obtained when using the alignment with regions of interest, we found a better dimensional similarity between the reference model M1 and model M3 (obtained using the intraoral scanner) compared to the model M2 (obtained using the extraoral scanner). The best similarity was found when comparing the models M2 and M3 (Fig. $6)$.

Furthermore, compared to the reference model M1, we noticed that the extraoral scanner tends to underestimate the model dimensions, a good proportion of the values outside the tolerances being below the reference value, while the intraoral scanner tends to overestimate them. 7).

Using automatic alignment, the results obtained are similar to the alignment performed by regions of interest (Fig.

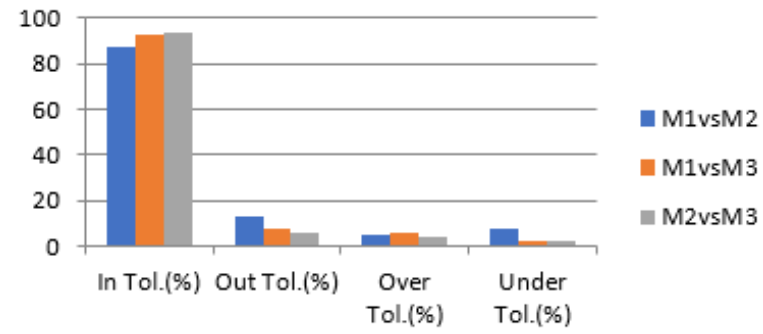

Fig. 6. Results obtained from the comparison between models with the alignment conditioned by the region of interest

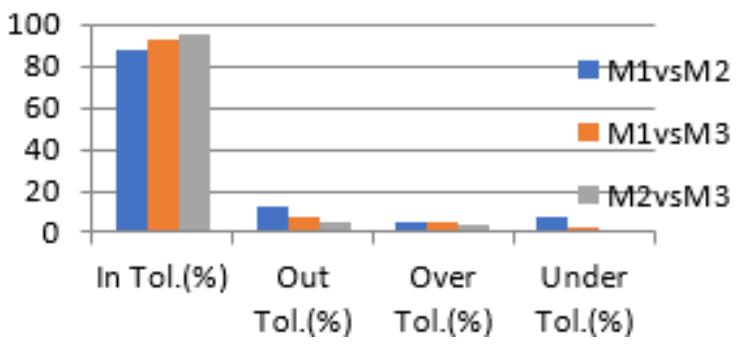

Fig. 7. Results obtained from the comparison between models with automatic alignment 
These in vitro study results show that the printed model obtained after intraoral scanning has a better compatibility with the reference model and that the type of scanner used influences the results of the measurement. Moreover, the methods of analysis by various types of alignment of the models in order to compare them influence the results of the measurements, and the accuracy of an extraoral scanner seems to be affected, mostly, by underestimation of dimensional values, and that of an intraoral scanner by overestimation of dimensional values.

The results obtained in this scientific research, are generally in agreement with those obtained by other studies found in the scientific literature. There are, at the same time, some reports in the literature that are different from the results of the present study. For example, Alshawaf et al., (2018) [5] mention that, when performing fixed prosthetic restorations supported by dental implants in case of Kennedy's Class II edentations, the printed models generated after intraoral scanning have an inferior accuracy to the conventional gypsum models made after an open-tray impression. Ji-Young Sim [16] publishes a study according to which 3D printed models have a lower accuracy compared to conventional ones. A scientific research by Chris Bocklet et al. [17] shows that scanning the entire dental arch with an intraoral scanner is less accurate than scanning with an extraoral scanner, and the results of the study carried out by Gun-Hong et al. (2019) [18] highlights that the highest accuracy of the entire dental arch was obtained by extraoral scanning.

However, in the recent years, the scientific literature provides abundant information on positive results obtained by intraoral scanning, which are in agreement with the results of our scientific research. Ender et al. (2019) [19], specifies that: "certain current IOS devices are well within the required accuracy required for full-arch scans" and - corresponding to partial-arch impressions - "IO scanninig represents a suitable alternative to conventional impression methods". The intraoral scanning is described by many authors as being able to provide greater accuracy of dental models, compared to the laboratory (extraoral) scanning or to the conventional method of obtaining dental models, represented by conventional oral impression [20, 21, 22, 14]. Sason et al. (2018) [20] presented an in vivo study performed on 10 clinically healthy patients, aged 18-45, highlighting that the intraoral scanner offers greater accuracy (precision and trueness) than the extraoral scanner. Intraoral scanners can be used, according to Nedelcu et al., (2018) [21], as "replacements" of conventional impressions, when at most 10 dental units are prosthetically restored. Other studies confirm that the dental models obtained by intraoral scanning have dimensional accuracy "equivalent or higher" to that of the gypsum models obtained by conventional oral impression (Serag et al., 2018) [22]. Moreover, Tomita et al. (2018) [23], as well as Bosniac, Rehmann and Woestmann (2018) [24] confirm that intraoral scans may be more accurate than conventional oral impressions or gypsum model scans.

A recent scientific research (2019) [25] reveals that, although dental models printed using the SLA (stereolithography) technique did not show better fidelity than conventional gypsum dental models, no statistically significant difference was observed between the two types of models. In terms of accuracy, the dental models printed by the SLA technique showed better results than the gypsum models. Summarising the results, the authors conclude that the analysed printed models provided sufficient accuracy for clinical applicability.

The use of digital models as an alternative to conventional ones, made of gypsum, has been recommended and successfully used for many years in orthodontics, for specific measurements (2011) [26]. In connection with the printing techniques of 3D dental models, some studies claim that the PolyJet and DLP (digital light processing) printing methods allow to obtain more accurate models than the SLA (stereolithography) or FFF (fused filament fabrication) methods [27]. Camardella et al. (2017) [28], find that the printed models made by the PolyJet technique have appropriate accuracy, regardless of the base model (full/regular base; arcade/horseshoe; arch with posterior reinforcement bar), while the models printed by SLA technique (stereolithography) show statistically significant differences (transverse contraction) in terms of accuracy. The models printed by SLA with the posterior reinforcement bar showed better accuracy than those with the regular base [28]. Another interesting aspect is the analysis of the printed models versus the milled models. Thus, compared to the subtractive process (milling), the additive process (printing) is considered to be superior, allowing to obtain more complex dental models, as well as prosthetic restorations that cannot be made so accurately by milling $[29,30]$.

$3 \mathrm{D}$ printing and intraoral scanning represent topics of great interest in the modern scientific research, showing a significant development [31-34], with extremely promising perspectives; therefore, the dentistry of the future has every chance to become "3D printed", and the acquisition of the necessary data for the elaboration and implementation of the treatment plans shall be mostly or - perhaps - exclusively done in the dental office.

\section{Conclusions}

Within the limitations of this study, the following conclusions can be drawn: the observed dimensional diferences could be mainly attributed to the type of scanner that was used in obtaining the 3D printed dental models; the 3D printed dental model obtained via IO scanning showed slightly improved dimensional compatibility with the reference model in comparison with the one produced via EO scanning; the performed analysis indicated overestimated dimensional values corresponding to the printed model obtained by using the IO scanner and underestimated ones corresponding to the 3D printed model obtained by using the EO scanner. Further in vivo and in vitro studies are currently performed to support these results. 
Acknowledgement: The authors gratefully acknowledge the support that "Dr. Fischer Dental Lab", "F.M. Medident - Institute for Dental Radiology" and "Top Metrology S.R.L."/ Bucharest, Romania provided during this study.

\section{References}

1. FLUGGE, T.V., SCHLAGER, S., NELSON, K., NAHLES, S., METZGER, M.C. Am. J. Orthod. Dentofacial Orthop., 144(3), 2013, p. 471478

2. MANGANO, F., GANDOLFI, A, LUONGO, G, LOGOZZO, S., BMC Oral health, 17(1), 2017, p. 149

3. MUHLEMANN, S., GRETER, E. A., PARK, J-M, HAMMERLE, C.H.F., THOMA, D.S., Clinical Oral Implants Research, 29(9), 2018, p. 931-936

4. BOHNER, 1., HANISCH, M., DE LUCA CANTO, G., MUKAI, E., SESMA, N., TORTAMANO, P., Journal of Oral Implantology, 45(2), 2019, p. 94-99

5. ALSHAWAF, B., WEBER, H.P., FINKELMAN, M., EL RAFIE, K., KUDARA, Y., PAPASPYRIDAKOS, P., Clinical Oral Implants Research., 29(8), 2018, p. 835-842

6. PEDROCHE, L.O., BERNARDES, S.R., LEÃO, M.P., KINTOPP, C.C., CORRER, G.M., ORNAGHI, B.P., GONZAGA, C.C., Braz. Oral. Res., 30(1), 2016, p. 113

7. KEUL, C., STAWARCZYK, B., ERDELT, K.J., BEUER, F., EDELHOFF, D., GÜTH, J.F., Dent. Mater., 30(4), 2014 , p. 400-407

8. ALMEIDA E SILVA, J.S., ERDELT, K., EDELHOFF, D., ARAÚJO, E., STIMMELMAYR, M., VIEIRA, L.C., GÜTH, J.F., Clin. oral. investig., 18(2), 2014, p. 515-523

9. UEDA, K., BEUER, F., STIMMELMAYR, M., ERDELT, K., KEUL, C., GÜTH, J.F., Clin oral investig., 20(2), 2016, p. 283-289

10. TAKEUCHI, Y., KOIZUMI, H., FURUCHI, M., SATO, Y., OHKUBO, C., MATSUMURA, H., Journal of Oral Science, 60(1), 2018, p. 1-7

11. SYREK, A., REICH, G., RANFTL, D., KLEIN, C., CERNY, B., BRODESSER, J., J. Dent., 38(7), 2010, p. 553-559

12. PRADIES, G., ZARAUZ, C., VALVERDE, A., FERREIROA, A., MARTINEZ-RUS, F., J. DENT., 43(2), 2015, p. 201-208

13. RODIGER, M., HEINITZ, A., BURGERS, R., RINKE, S., Clin. Oral Investig., 21(2), 2017, p. 579-587

14. TANCU, A.M.C., PANTEA, M., TOTAN, A., TANASE, M., IMRE. M., 2019; Mat. Plast., 55, no 1, 2019, p. 51-4

15. BROWN, G.B., CURRIER, G.F., KADIOGLU, O., KIERL., J.P., Am. J. Orthod. Dentofacial Orthop., 154(5), 2018, p. 733-739

16. SIM, J.Y., JANG, Y., KIM, W.C., KIM, H.Y., LEE, D.H., KIM, J.H., Journal of Prosthodontic Research, 63(1), 2019, p. 25-30

17. BOCKLET, C., RENNE, W., MENNITO, A., BACRO, T., LATHAM, J., EVANS, Z., LUDLOW, M., KELLY A., NASH, J., 2019, https://doi.org/10.1111/ocr.12273

18. PARK, G.H., SON, K.., LEE, K.B., Journal of Prosthetic Dentistry, 121(5), 2019, p. 803-810

19. ENDER, A., ZIMMERMANN, M., MEHL, A., International Journal of Computerized Dentistry, 22(1), 2019, p. 11-19

20. SASON, G.K., MISTRY, G., TABASSUM, R., SHETTY, O., Journal of Indian Prosthodontic Society, 18(2),2018, p. 108-116

21. NEDELCU, R., OLSSON, P., NYSTROM, I., RYDEN, J., THOR, A, J. Dent., 69, 2018, p. 110-118

22. SERAG, M., AL NASSAR, T, AVONDOGLIO, D., WEINER, S., Journal of Prosthodontics, 27(1), 2018, p. 88-93

23. TOMITA Y., UECHI, J., KONNO, M., SASAMOTO, S., IIJIMA, M., MIZOGUGHI, I., Dental Materials Journal, 37(4), 2018, p. 628-633

24. BOSNIAC, P., REHMANN, P. \& WÖSTMANN, B. Clin Oral Invest, 23(5), 2019, p. 2421-2427

25. SU-JIN JIN, DONG-YEON KIM, JI-HWAN KIM, WOONG-CHUL KIM. Journal of Prosthodontics, 28, 2019, p. 557-562

26. FLEMING, P.S., MARINHO, V., JOHAL, A., Orthod. Craniofac. Res., 24, 2011, p. 1-16

27. SOO-YEON KIM, YOO-SEOK SHIN, HWI-DONG JUNG, CHUNG-JU HWANG, HYOUNG-SEON BAIK, JUNG-YUL CHA. American Journal of Orthodontics and Dentofacial Orthopedics, 153(1), 2018, p. 144-153

28. CAMARDELLA, L.T., OSWALDO DE VASCONCELLOS VILELLA, BREUNING, H., Ajo-Do., 151(6), 2017, p. 1178-118

29. YOSHIKI ISHIDA, TAIRA MIYASAKA, Dent. Mater. J., 35(2), 2016, p. 250-256

30. JEONG, Y.G., LEE, W.S., LEE, K.B., J. Adv. Prosthodont., 10(3), 2018, p. 245-251

31. MELESCANU-IMRE, M., PANTEA, M, TOTAN, A., TANCU, A.M.C., GREABU, M., TOTAN, C., SPINU, T.C., Mat. Plast., 56, no 2, 2019, p. 409-412

32. POPA, A., FAUR, N., HLUSCU, M., BELIN, C., Mat. Plast., 56, no 3, 2019, p. 500-504

33. TOTU, E.E., CRISTACHE, C.M., ISILDAK, S., TAVUKCUOGLU, O., PANTAZI, A., ENACHESCU, M., BUGA, R., BURLIBASA, M., TOTU, T., Mat. Plast., 55, no 4, 2018, p. 616-619

34. ANDREESCU, C.F., GHIERGIC, D.L., BOTOACA, O., HANCU, V., BANATEANU, A.M., PATROI, D.N., Mat. Plast., 55, no 4, 2018 , p. 124-8

Manuscript received: 31.10 .2019 